\title{
Prevalência e perfil de sensibilidade dos gêneros Klebsiella spp. e Staphylococcus spp. isolados da urocultura de pacientes de um laboratório privado de análises clínicas no município de Conselheiro Lafaiete-MG/Brasil
}

\author{
Prevalence and sensitivity profile of the genus Klebsiella spp. and Staphylococcus spp. isolated in \\ urocultures from patients in a private laboratory of clinical analyses in Conselheiro Lafaiete-
} MG/Brazil

Prevalencia y perfil de sensibilidad de los géneros Klebsiella spp. y Staphylococcus spp. aislados en cultivos de orina de pacientes en un laboratorio privado de análisis clínicos en Conselheiro

Lafaiete-MG/Brasil

\author{
Rubens Barbosa Rezende \\ ORCID: https://orcid.org/0000-0002-5421-0519 \\ Faculdade Santa Rita, Brasil \\ E-mail: rubensrezende420@gmail.com \\ Isadora Moreira Costa do Nascimento Nogueira \\ ORCID: https://orcid.org/0000-0001-8293-9465 \\ Faculdade Santa Rita, Brasil \\ E-mail: nogueira_isadora@yahoo.com.br
}

\begin{abstract}
Resumo
Objetivou-se avaliar a prevalência e o perfil de sensibilidade aos antimicrobianos dos gêneros Klebsiella spp. e Staphylococcus spp. isolados de amostras de urinas de mulheres provenientes de um Laboratório privado de Análises Clínicas no município de Conselheiro Lafaiete-MG, bem como a estação de maior prevalência. Foi realizado um estudo observacional transversal, do tipo quantitativo, visando à coleta de dados secundários sobre a prevalência e o perfil de sensibilidade dos gêneros Klebsiella spp. e Staphylococcus spp. isolados das uroculturas positivas em pacientes do gênero feminino com faixa etária entre 18 a 60 anos, no período de janeiro a dezembro de 2019 . No período do estudo foram identificadas neste laboratório 41 uroculturas positivas provenientes de mulheres dentro da faixa etária estipulada, sendo o gênero Klebsiella spp. o mais prevalente 13/41 (31,71\%), seguido do Staphylococcus spp. 11/41 (26,83\%). A partir dos resultados obtidos neste estudo, foi possível identificar que todos os objetivos foram alcançados, uma vez que se obteve o número de casos de infecções em pacientes do gênero feminino entre 18 a 60 anos, foi avaliado a estação com maior prevalência de infecção do trato urinário, apresentou-se em tabelas os patógenos de interesse, e descrito o perfil de sensibilidade das bactérias aos principais antimicrobianos de relevância clínica.
\end{abstract}

Palavras-chave: Bactérias; Infecções; Infecções bacterianas; Infecções urinárias.

\begin{abstract}
The objective was to evaluate the prevalence and antimicrobial sensitivity profile of Klebsiella spp. and Staphylococcus spp. isolated from urine samples of women from a private Laboratory of Clinical Analysis in Conselheiro Lafaiete-MG, as well as the season of higher prevalence. A cross-sectional observational study of the quantitative type was conducted, aiming to collect secondary data on the prevalence and sensitivity profile of Klebsiella spp. and Staphylococcus spp. genera isolated from positive urine cultures in female patients aged 18 to 60 years, in the period from January to December 2019. During the study period, 41 positive urine cultures were identified in this laboratory from women within the stipulated age range, with the genus Klebsiella spp. being the most prevalent 13/41 (31.71\%), followed by Staphylococcus spp. 11/41 (26.83\%). From the results obtained in this study, it was possible to identify that all the objectives were achieved, since the number of cases of infections in female patients between 18 and 60 years of age was obtained, the season with the highest prevalence of urinary tract infection was evaluated, the pathogens of interest were presented in tables, and the sensitivity profile of bacteria to the main antimicrobials of clinical relevance was described.
\end{abstract}

Keywords: Bacteria; Bacterial infections; Infections; Urinary infections. 


\begin{abstract}
Resumen
El objetivo de este estudio fue evaluar la prevalencia y el perfil de sensibilidad antimicrobiana de Klebsiella spp. y Staphylococcus spp. aislados de muestras de orina de mujeres de un Laboratorio de Análisis Clínicos privado de Conselheiro Lafaiete-MG, así como la estación de mayor prevalencia. Se realizó un estudio observacional transversal de tipo cuantitativo, con el objetivo de recopilar datos secundarios sobre la prevalencia y el perfil de sensibilidad de los géneros Klebsiella spp. y Staphylococcus spp. aislados a partir de urocultivos positivos en pacientes femeninas de entre 18 y 60 años, en el periodo comprendido entre enero y diciembre de 2019. Durante el periodo de estudio, se identificaron en este laboratorio 41 urocultivos positivos de mujeres dentro del grupo de edad estipulado, siendo el género Klebsiella spp. el más prevalente 13/41 (31,71\%), seguido de Staphylococcus spp. 11/41 (26,83\%). A partir de los resultados obtenidos en este estudio, se pudo identificar que todos los objetivos fueron alcanzados, ya que se obtuvo el número de casos de infecciones en pacientes mujeres de entre 18 y 60 años, se evaluó la estación con mayor prevalencia de la infección del tracto urinario, se presentaron los patógenos de interés en tablas y se describió el perfil de sensibilidad de las bacterias a los principales antimicrobianos de relevancia clínica.
\end{abstract}

Palabras clave: Bacterias; Infecciones; Infecciones bacterianas; Infecciones del tracto urinario.

\title{
1. Introdução
}

A infecção do trato urinário (ITU) é determinada pela presença de microrganismos patogênicos que invadem os tecidos urinários, e de acordo com sua localização é classificada em infecção urinária baixa e alta (Oliveira \& Santos, 2018). Segundo Tortora e colaboradores (2017), as ITU são descritas em fases distintas, desde uma uretrite a uma pielonefrite. Inicialmente, é constatada a inflamação da uretra (uretrite), e se não tratada, a princípio, essa inflamação pode atingir por via ascendente a bexiga (cistite) e com capacidade de acometer os ureteres (ureterite). O risco mais significativo deste tipo de infecção é que os microrganismos podem se deslocar pelos ureteres, alcançando os rins (pielonefrite). Em casos mais graves, podem-se evoluir a septicemia, o que poderá culminar em óbito do paciente. Segundo Oliveira \& Santos (2018) no Brasil, as ITU são descritas como infecções bacterianas mais comuns, sendo responsáveis por 80 em cada 1.000 consultas clínicas. A etiologia e a prevalência das ITUs necessitam de vários fatores como: distribuição geográfica, idade, sexo, comorbidades concomitantes, dentre outras (Catto et al., 2016).

O sexo feminino se comparado ao masculino é mais vulnerável, e isso se dá pela anatomia da uretra ser mais curta e da proximidade da genitália feminina com o ânus, sendo a via ascendente a sua principal via de contaminação. A probabilidade de uma mulher na fase adulta desenvolver ITU é de cinquenta (50) vezes superior quando comparada aos homens (Roriz et al., 2010). É significativa a parcela de mulheres acometidas, incluindo variadas faixas etárias, especialmente nos períodos pré e pós gestacional (acomete de 10\% a 12\% das gestantes) (Lima \& Lima, 2018; Carvalho et al., 2018). Segundo Piçarra (2015) a flora presente na porção distal da uretra é maioritariamente composta por bactérias Gram-positivo (S. epidermidis, Streptococcus spp. e Lactobacillus spp.), que desempenham um papel de defesa local.

As ITUs podem ser classificadas como sintomáticas ou assintomáticas. Os sinais e sintomas relacionados a esta infecção são poliúria, disúria, alteração na cor e no aspecto da urina e odor forte, podendo também ocorrer febre e dores abdominais no paciente (Braggiato \& Lazar, 2016). Elas são de grande relevância clínica pelo fato dos agentes etiológicos desenvolverem mecanismos de resistência, isso acontece devido ao uso exacerbado e inapropriado dos antimicrobianos, principalmente no âmbito nosocomial, uma vez que deveria ser realizada de forma racional a prescrição do fármaco de acordo com o diagnóstico concreto e não com base em dados epidemiológicos frente às principais bactérias relacionadas a estas infecções (Kadosaki et al., 2012; Loureiro et al., 2016).

A origem da resistência bacteriana se dá por mutação e recombinação de genes, outro fato relacionado é a ausência de antimicrobianos para serem usados na terapia de casos mais graves, sendo necessários antibióticos de última geração; porém, o número de resistências bacterianas é mais rápido do que o processo de descobrimento de novos antimicrobianos (Grillo et al., 2013; Loureiro et al., 2016). Para a prevenção das complicações geradas pela ITU, é importante o diagnóstico precoce, bem 
Research, Society and Development, v. 11, n. 1, e32811124855, 2022

(CC BY 4.0) | ISSN 2525-3409 | DOI: http://dx.doi.org/10.33448/rsd-v11i1.24855

como a identificação do microrganismo envolvido e seu perfil de suscetibilidade aos antimicrobianos, que conduzirão ao tratamento adequado (Figueiredo et al., 2012; Duarte et al., 2008). Dentre as bactérias envolvidas em ITU, tem-se as espécies Staphylococcus saprophyticus, Proteus mirabilis, Streptococcus agalactiae e o gênero Klebsiella spp. Também podem acometer, esporadicamente, fungos do gênero Candida spp. (Kaper, 2004; Alós, 2005; Schenkel et al., 2014).

Assim, devido as ITU apresentarem importante relevância clínica sendo responsáveis por 80 em cada 1.000 consultas, pelo fato dos agentes etiológicos desenvolverem mecanismos de resistência aos antimicrobianos, e por serem classificadas como infecções bacterianas mais comuns, é significativo a parcela de mulheres acometidas, incluindo variadas faixas etárias, especialmente nos períodos pré e pós-gestacional (acomete de $10 \%$ a $12 \%$ das gestantes). E de acordo com Lima \& Lima (2018) e Carvalho et al. (2018) foi estimado que, mais de 50\% das mulheres apresentaram um episódio de ITU durante a vida e pelo menos $25 \%$ tiveram uma ou mais recorrências, justificando-se assim, a realização do presente trabalho. Para tanto, no presente estudo teve-se como objetivo avaliar a prevalência e o perfil de sensibilidade aos antimicrobianos dos gêneros Klebsiella spp. e Staphylococcus spp. isolados de amostras de urinas de pacientes de um Laboratório privado de Análises Clínicas no município de Conselheiro Lafaiete-MG, bem como a estação de maior prevalência de ITU.

\section{Metodologia}

Trata-se de um estudo observacional, de acordo Cervo e Bervian (2002, p. 27), que dizem: "observar é aplicar atentamente os sentidos físicos a um amplo objeto, para dele adquirir um conhecimento claro e preciso", e transversal, que segundo Rouquayrol (1994), define tal pesquisa como um estudo epidemiológico no qual fator e efeito são observados num mesmo momento histórico.

Possui natureza quantitativa, caracterizada pelo emprego da quantificação, tanto nas modalidades de coleta de informações quanto no tratamento delas por meio de técnicas estatísticas (Richardson, 1999). E quanto à técnica de coleta de dados, segundo Lakatos e Marconi (2001) é designada como um conjunto de regras ou processos utilizados por uma ciência, ou seja, corresponde à parte prática da coleta de dados, tratando-se de dados secundários sobre a prevalência e o perfil de sensibilidade dos gêneros Klebsiella spp. e Staphylococcus spp. isolados das uroculturas positivas em pacientes do gênero feminino com faixa etária entre 18 a 60 anos, atingindo jovens, adultas e idosas.

De início foi feita a Semeadura com Alça Calibrada, sendo esse método caracterizado pelo uso da urina não diluída, utilizando-se uma alça de platina de diâmetro calibrado capaz de carrear uma quantidade fixa de urina $(0,001$ ou $0,01 \mathrm{~mL})$, o que padroniza desse modo o fator de diluição (Brasil, 2013). Foram consideradas culturas positivas as placas que apresentaram contagem de unidades formadoras de colônia (UFC) por mililitro $(\mathrm{mL})$ de urina não centrifugada maior ou igual a $10^{5}$ UFC/mL, de acordo com as recomendações do Clinical and Laboratory Standards Institute (Clsi, 2014), mesmo que alguns desses exames fossem realizados pela mesma paciente, em ocasiões diferentes, uma vez que não foram avaliados casos de recidiva ou reinfecção, visto que a coleta dos dados foi realizada a partir do número de identificação de entrada da amostra do paciente e não de forma nominal. As informações obtidas foram referentes ao ano de 2019.

Para o isolamento dos microrganismos, foram utilizados ágar Cistina Lactose Eletrólito Deficiente (CLED) e ágar Sangue. A identificação das bactérias nas culturas foi executada através de bioquimismo clássico. Os antibiogramas foram feitos utilizando a técnica de disco-difusão em ágar, proposta por Bauer e Kirby (1966), utilizando o ágar Müller-Hinton, a incubação das placas de Petri contendo o ágar de escolha e a semeadura foi realizada em estufa bacteriológica à temperatura de $37^{\circ} \mathrm{C} \pm 1^{\circ} \mathrm{C}$ por 24 horas.

O laboratório onde os dados foram obtidos está localizado no município de Conselheiro Lafaiete, Minas Gerais, região sudeste do Brasil, ocupando uma área territorial de $369.544 \mathrm{~km}^{2}$, (Figura 1). Sua população é composta por 129.606 
habitantes segundo o último censo demográfico em 2010 (IBGE, 2019).

Figura 1 - Localização do município de Conselheiro Lafaiete no território nacional, Brasil (à esquerda), e localização na macrorregião do Alto Paraopeba (à direita), 2019.
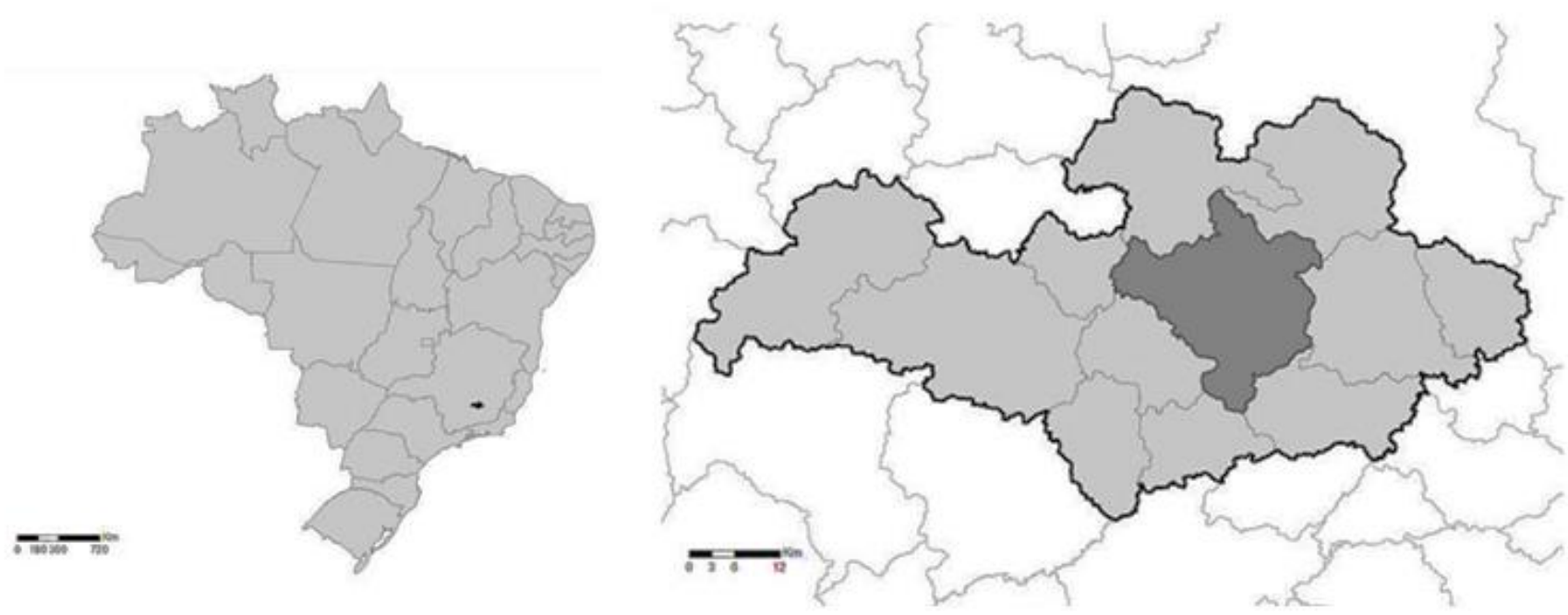

Nota: [à direita] macrorregião do Alto Paraopeba (cinza claro e contornado), e município de Conselheiro Lafaiete (cinza escuro). Fonte: adaptado de Silva et al., (2019), p. 6.

Foram utilizados artigos científicos, teses e dissertações encontrados em bases de dados como Scientific Eletronic Library Online (SCIELO), Literatura Latino Americana e do Caribe em Ciências da Saúde (LILACS) e Sistema Online de Busca e Análise de Literatura Médica (MEDLINE), e no site da Agência Nacional de Vigilância Sanitária (ANVISA), como também em livros de Microbiologia. Esta pesquisa foi aprovada pelo Comitê de Ética em Pesquisa, número do parecer: 4.038.670.

\section{Resultados e Discussão}

No período em estudo, 470 uroculturas foram realizadas no Laboratório de Análises Clínicas. Destas, 226 (48,09\%)

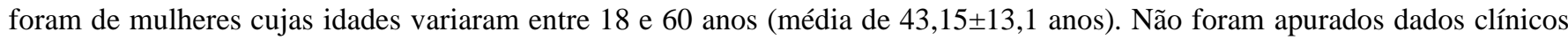
das pacientes e não foram descritos os exames que correspondem a casos de ITU sintomática ou de bacteriúria assintomática. Entre as 226 uroculturas positivas, 41 foram das bactérias de interesse para este trabalho, sendo elas 19 (46,34\%) corresponderam a bactérias Gram negativas, $22(53,65 \%)$ a bactérias Gram positivas.

Como o principal caminho utilizado pelos uropatógenos é a via ascendente, as circunstâncias anatômicas da genitália da mulher são fatores significativos de predisposição (Masson et al., 2009). Outrossim, a diminuição da capacidade vesical e secreção vaginal, o enfraquecimento do assoalho da pélvis e as alterações tróficas do epitélio pela redução dos níveis hormonais (estrogênio) contribuem para a ausência da microbiota vaginal (constituída por Lactobacillus spp.), propiciando a colonização microbiana patogênica (Koneman, 2008).

Pires e colaboradores (2007) dizem que o exame visto como padrão ouro para diagnóstico da infecção urinária é a urocultura, pois é um importante método que caracteriza e quantifica as bactérias que proporcionam a infecção no indivíduo, permitindo assim o seu isolamento para consecutivo estudo da sensibilidade frente aos antimicrobianos por meio do 
antibiograma.

Entre as bactérias isoladas de interesse ao presente trabalho, o gênero Klebsiella spp. foi o mais prevalente 13/226 (5,75\%), seguido da espécie Staphylococcus aureus e do gênero Staphylococcus spp. ambos, com 11/226 (4,87\%), as espécies Klebsiella pneumoniae e Klebsiella ozaenae ficaram com 5/226 (2,21\%) e 1/226 (0,44\%), respectivamente (Tabela 1).

Tabela 1 - Prevalência de microrganismos em uroculturas de mulheres entre 18 a 60 anos no período de janeiro a dezembro de 2019.

\begin{tabular}{ccc}
\hline \multirow{2}{*}{ Bactérias } & \multicolumn{2}{c}{ Prevalência } \\
\cline { 2 - 3 } & $\mathrm{n}$ & $(\%)$ \\
\hline Klebsiella spp. & 13 & 5,75 \\
Staphylococcus aureus & 11 & 4,87 \\
Staphylococcus spp. & 11 & 4,87 \\
Klebsiella pneumoniae & 5 & 2,21 \\
Klebsiella ozaenae & 1 & 0,44 \\
Outras & 185 & 81,86 \\
\hline Total & 226 & 100 \\
\hline
\end{tabular}

Fonte: Dados da pesquisa (2020).

Brambilla e colaboradores (2019) em seu trabalho realizado em um laboratório da região do Noroeste do Paraná, mostraram resultados semelhantes aos obtidos neste presente estudo, no qual o gênero Klebsiella spp. foi o mais prevalente em seu estudo (5,75\%), o que se encontra em conformidade com outros autores, uma vez que o gênero Klebsiella spp. também é um gênero de bactérias bacilares, gram-negativas (Moura, 2011).

Menin e Graziotin (2010), na cidade de Campus de Erechim/RS, observaram uma espécie pouco comum como a Klebsiella ozaenae, sua prevalência foi de 1/36 (2,77\%), e no presente estudo foi de 1/226 (0,44\%). Trata-se de um subtipo de K. pneumoniea, e tem sido um motivo conhecido de doença inflamatória crônica das vias aéreas superiores, além de ITU, abscesso hepático, infecções de tecidos moles, dentre outras patologias (Abbas et al., 2019).

O antibiograma é tido como uma das provas mais relevantes para tratamento de ITU, pois trata-se de um método de fácil execução e por ser prático. Devido à grande diversidade de antimicrobianos no mercado, é essencial a análise destes medicamentos em relação aos agentes etiológicos da ITU, deste modo agindo de forma preventiva ao fracasso terapêutico e a provável resistência bacteriana (Santos et al., 2012; Apolinário et al., 2014).

Dentre as bactérias mais prevalentes no intervalo pesquisado de acordo com o objetivo central do trabalho, e analisadas em relação à sensibilidade aos antimicrobianos, tem-se as Gram negativas (Klebsiella spp.; K. pneumoniae e K. ozaenae), correspondendo a 19 uroculturas, e as Gram positivas (Staphylococcus aureus e Staphylococcus spp.), correspondendo a 22. O gênero Klebsiella spp. demonstrou resistência para ampicilina (100\%) e sensibilidade a nitrofurantoína (100\%), já as espécies K. pneumoniae e K. ozaenae apresentaram, ambas, 100\% de resistência também a ampicilina e 100\% de sensibilidade a ceftriaxona, conforme a (Tabela 2). 
Tabela 2 - Perfil de sensibilidade das bactérias Gram negativas mais frequentemente isoladas ( $\mathrm{n}=19)$ em uroculturas de mulheres entre 18 a 60 anos no período de janeiro a dezembro de 2019

\begin{tabular}{|c|c|c|c|c|c|c|}
\hline \multirow[b]{2}{*}{ Agente antimicrobiano } & \multicolumn{2}{|c|}{$\begin{array}{l}\text { Klebsiella spp. } \\
\quad(\mathrm{n}=13)\end{array}$} & \multicolumn{2}{|c|}{$\begin{array}{l}\text { Klebsiella pneumoniae } \\
(\mathrm{n}=5)\end{array}$} & \multicolumn{2}{|c|}{$\begin{array}{l}\text { Klebsiella ozaenae } \\
\quad(\mathbf{n}=\mathbf{1})\end{array}$} \\
\hline & $\mathrm{S}(\%)$ & $\begin{array}{l}\mathrm{R} \\
(\%)\end{array}$ & $\mathrm{S}(\%)$ & $\begin{array}{c}\mathrm{R} \\
(\%)\end{array}$ & $\mathrm{S}(\%)$ & $\mathrm{R}(\%)$ \\
\hline Ciprofloxacina & 92,3 & 7,7 & 80 & 20 & 100 & 0 \\
\hline Norfloxacina & 92,3 & 7,7 & 80 & 20 & 100 & 0 \\
\hline Ampicilina & 0 & 100 & 0 & 100 & 0 & 100 \\
\hline Nitrofurantoina & 100 & 0 & 80 & $*$ & 100 & 0 \\
\hline Sulfazotrim & $*$ & 7,7 & $*$ & $*$ & $*$ & $*$ \\
\hline Gentamicina & 76,92 & 15,4 & 80 & $*$ & 100 & 0 \\
\hline Amoxicilina/clavulanato & 84,61 & 15,4 & 60 & $*$ & 100 & 0 \\
\hline Ampicilina/sulbactan & 92,3 & * & 80 & $*$ & 100 & 0 \\
\hline Ceftriaxona & 100 & $*$ & 100 & 0 & 100 & 0 \\
\hline Sulfametoxazol/trimetoprima & 92,3 & $*$ & 20 & 10 & 100 & 0 \\
\hline
\end{tabular}

Nota: S, suscetível; R, resistente; *não calculado. Fonte: Dados da pesquisa (2020).

Araújo e colaboradores (2017) evidenciaram a capacidade dos microrganismos se tornarem resistentes ao uso clínico dos antimicrobianos, enfatizaram ainda que tal resistência pode ser passada por fatores genéticos, tais como as mutações, e variavam conforme a situação do paciente, como por exemplo faixa etária, recidiva de ITU e o uso inapropriado destes medicamentos.

O gênero Klebsiella spp. se mostrou resistente a ampicilina 100\%, o que corrobora com o trabalho de Lima (2017) em que a ampicilina apresentou 94\% estando bem próximo do resultado encontrado. Em relação ao perfil de sensibilidade ela apresentou $100 \%$ para ceftriaxona, $84,61 \%$ para amoxicilina/clavulanato e 92,3\% para ciprofloxacina, norfloxacina, ampicilina/sulbactan e sulfametoxazol/trimetoprima. No trabalho de Dias e colaboradores (2015), a sensibilidade encontrada foi de $83,3 \%$ a $100 \%$ para ceftriaxona, ciprofloxacina e norfloxacina, os outros antibióticos não foram testados, e tais valores estão de acordo com o presente estudo. Já em Lima (2017), em sua pesquisa, os resultados foram todos menores se comparados com o presente trabalho, ceftriaxona apresentou $41 \%$, amoxicilina/clavulanato $75 \%$, ciprofloxacina $75 \%$, norfloxacina $42 \%$, ampicilina/sulbactan (não testado) e sulfametoxazol/trimetoprima 18\%. Contudo, o gênero Klebsiella spp. apresentou sensibilidade à classe dos aminoglicosídeos (Gentamicina), 76,92\%, o que se assemelha com o estudo de Dias et al. (2015), onde o gênero demonstrou sensibilidade de $83,3 \%$ a $100 \%$.

Já para a K. pneumoniae, demonstrou resistência para o antibiótico ampicilina (100\%), estando de acordo com o trabalho de Machado et al. (2017), em que se teve o mesmo percentual. Bem como corrobora com os resultados obtidos na pesquisa de Santana et al. (2012) em que obtiveram uma resistência de $90 \%$ da K. pneumoniae frente a ampicilina em pacientes ambulatoriais. E esse elevado índice de resistência da $K$. pneumoniae para a ampicilina exibida no presente trabalho está associada com o fato dessa bactéria possuir resistência intrínseca ao antimicrobiano em questão, segundo descrito na literatura (Clsi, 2012).

Entre as bactérias mais prevalentes Gram positivas, a espécie Staphylococcus aureus apresentou frente à amoxicilina/clavulanato, ampicilina/sulbactan, ceftriaxona, ciprofloxacina e nitrofurantoina 100\% de sensibilidade e para norfloxacina, gentamicina, sulfametoxazol/trimetoprima e tetraciclina 90,9\% de sensibilidade, já ampicilina apresentou sensibilidade de $81,81 \%$. Dentre os antibióticos testados para a referida bactéria, obteve-se resistência em ampicilina, penicilina e eritromicina, $18,19 \% ; 9,1 \%$ e $9,1 \%$, respectivamente, dispostos na (Tabela 3 ). 
Tabela 3 - Perfil de sensibilidade das bactérias Gram positivas mais frequentemente isoladas (n=22) em uroculturas de mulheres entre 18 a 60 anos no período de janeiro a dezembro de 2019.

\begin{tabular}{|c|c|c|c|c|}
\hline \multirow[b]{2}{*}{ Agente antimicrobiano } & \multicolumn{2}{|c|}{ Staphylococcus aureus $(\mathrm{n}=11)$} & \multicolumn{2}{|c|}{ Staphylococcus spp. $(\mathrm{n}=11)$} \\
\hline & $\mathrm{S}(\%)$ & $\mathrm{R}(\%)$ & $\mathrm{S}(\%)$ & $\mathrm{R}(\%)$ \\
\hline Ciprofloxacina & 100 & 0 & 81,81 & 18,19 \\
\hline Norfloxacina & 90,9 & * & 81,81 & 18,19 \\
\hline Ampicilina & 81,81 & 18,19 & 90,9 & 9,1 \\
\hline Nitrofurantoina & 100 & 0 & 90,9 & 9,1 \\
\hline Sulfazotrim & $*$ & $*$ & 9,1 & $*$ \\
\hline Gentamicina & 90,9 & $*$ & 100 & 0 \\
\hline Amoxicilina/clavulanato & 100 & 0 & 90,9 & $*$ \\
\hline Ampicilina/sulbactan & 100 & 0 & 81,81 & $*$ \\
\hline Ceftriaxona & 100 & 0 & 81,81 & 9,1 \\
\hline Sulfametoxazol/trimetoprima & 90,9 & $*$ & 90,9 & $*$ \\
\hline Tetraciclina & 90,9 & $*$ & 81,81 & 9,1 \\
\hline Rifampicina & 72,72 & $*$ & 36,36 & $*$ \\
\hline Clorafenicol & 54,54 & $*$ & 72,72 & $*$ \\
\hline Penicilina & 18,18 & 9,1 & 18,18 & 36,36 \\
\hline Vancominica & $*$ & $*$ & $*$ & $*$ \\
\hline Eritromicina & 9,1 & 9,1 & $*$ & $*$ \\
\hline Clindamicina & 45,45 & $*$ & $*$ & $*$ \\
\hline Oxacilina & 54,54 & $*$ & 36,36 & $*$ \\
\hline
\end{tabular}

Nota: S, suscetível; R, resistente; *não calculado. Fonte: Dados da pesquisa (2020).

O gênero Staphylococcus spp. apresentou frente à gentamicina $100 \%$ de sensibilidade, ampicilina, amoxicilina/clavulanato, sulfametoxazol/trimetoprima e nitrofurantoina 90,9\%, ciprofloxacina, norfloxacina, ampicilina/sulbactan, ceftriaxona e tetraciclina $81,81 \%$. E em relação a resistência teve-se a penicilina, norfloxacina e ciprofloxacina 36,36\%; 18,19\% e 18,19\%, respectivamente. O antibiótico com menor índice de resistência é a nitrofurantoína, pois se foi reduzido o seu uso em consequência dos seus efeitos colaterais e também a chegada de novos antibióticos (Araujo \& Queiroz, 2012; Dias et al., 2015).

A tabela 4 traz dados referentes as estações, em ordem decrescente fica o inverno (21 de junho a 23 de setembro) outono (21 de março a 21 de junho), primavera (23 de setembro a 21 de dezembro) e verão (21 de dezembro a 21 de março), e acredita-se que a taxa mais alta no inverno seja pela baixa ingesta de líquidos. E de acordo com Delgado (2021) no inverno, tomar água ao longo do dia tornou-se um hábito muito menos frequente. E essa alteração de comportamento é capaz de comprometer uma parte importante do organismo, o aparelho urinário. O risco de desencadear uma infecção urinária eleva de forma significativa, principalmente entre o sexo feminino. 
Tabela 4 - Influência da sazonalidade no quadro de prevalência de microrganismos em uroculturas de mulheres entre 18 a 60 anos no período de janeiro a dezembro de 2019, demonstrado em estações.

\begin{tabular}{cccccc}
\hline Bactérias & Verão & Outono & Inverno & Primavera & Total \\
\hline Staphylococcus spp. & 4 & 3 & 2 & 2 & 11 \\
Staphylococcus aureus & - & 4 & 3 & 4 & 11 \\
Klebsiella spp. & 2 & 2 & 8 & 1 & 13 \\
Klebsiella pneumoniae & - & 3 & 1 & 1 & 5 \\
Klebsiella ozaenae & - & - & - & 1 & 1 \\
\hline Total por estação & 6 & 12 & 14 & 9 & 41 \\
\hline
\end{tabular}

Fonte: Dados da pesquisa (2020).

De acordo com o dicionário Houaiss, o termo "sazonal" é descrito como "relativo a estação do ano; próprio de uma estação; estacional”. Altizer e colaboradores (2006) dizem que as alterações sazonais são cíclicas, bastante previsíveis, e sem dúvida retratam a mais poderosa e universal fonte de transformações externas que influenciam sistemas naturais e humanos. Para Rodrigues (2018) mesmo sendo conhecida a correlação entre doenças infecciosas e sazonalidade, tem-se poucas informações sobre os seus mecanismos e aspectos pouco compreendidos, os fatores associados a esse fenômeno e em particular nas infecções por bacilos gram negativos são ainda mais obscuros. Segundo Fisman (2007), as mudanças ambientais sazonais influenciam direta ou indiretamente na virulência de patógenos, como por exemplo, a temperatura, umidade e precipitação são determinantes na população, sobrevivência, virulência e transmissibilidade de patógenos.

A bactéria mais prevalente nas quatro estações foi a Gram negativa Klebsiella spp. 13/41 (31,70\%), tendo destaque no inverno, onde obteve maior prevalência se comparado aos outros meses, ficando com 8/41 (19,51\%). Enquanto que, as Gram positivas Staphylococcus aureus e Staphylococcus spp. tiveram maior frequência no outono 7/41 (17,07\%) e menor no verão $4 / 41(9,75 \%)$.

\section{Conclusão}

A partir dos resultados obtidos neste estudo, foi possível identificar que todos os objetivos foram alcançados, uma vez que se obteve o número de casos de infecções em pacientes do gênero feminino entre 18 a 60 anos, foi avaliado a estação com maior prevalência de ITU, apresentou-se em tabelas os patógenos de interesse, e descrito o perfil de sensibilidade das bactérias aos principais antimicrobianos de relevância clínica. Bem como, o gênero prevalente foi da Klebsiella spp. (5,75\%), demonstrando resistência para ampicilina (100\%) e sensibilidade a nitrofurantoína (100\%), já as espécies K. pneumoniae e K. ozaenae apresentaram, ambas, $100 \%$ de resistência também a ampicilina e 100\% de sensibilidade a ceftriaxona.

A resistência bacteriana é considerada um problema de saúde pública global e deve ser tratada com mais frequência. É importante ressaltar que os exames laboratoriais são essenciais para o diagnóstico correto e o subsequente tratamento eficaz, reduzindo assim o número de falhas no tratamento e a resistência bacteriana. O tratamento da ITU é principalmente empírico, o que ajuda a desenvolver resistência aos principais patógenos e seus medicamentos antibacterianos mais comumente usados. Portanto, é cada vez mais necessário realizar pesquisas sobre resistência bacteriana em diferentes regiões e o entendimento desse problema mundial.

Como também, se fazem necessários mais estudos robustos em relação as bactérias portadoras de $\beta$-lactamase de espectro estendido (ESBL), uma vez que infecções por agentes produtores de ESBL apresentam pior prognóstico, e são encontradas exclusivamente em bactérias Gram-negativas, particularmente as enterobactérias, incluindo o patógeno comum Klebsiella pneumoniae. 
Research, Society and Development, v. 11, n. 1, e32811124855, 2022

(CC BY 4.0) | ISSN 2525-3409 | DOI: http://dx.doi.org/10.33448/rsd-v11i1.24855

\section{Referências}

Abbas, A. F., Al-Saadi. A. G. M., Hussein, A. K., \& Al-Thaheb, A. O. (2019). Role of outer membrane proteins in virulence of Klebsiella ozaenae and antibiotic sensitivity. IOP Conf. Series: Journal of Physics: Conf. Series 1294, 062088. https://iopscience.iop.org/article/10.1088/1742$6596 / 1294 / 6 / 062088 /$ pdf

Alós, J. I. (2005). Epidemiology and etiology of urinary tract infections in the community. Antimicrobial susceptibility of the main pathogens and clinical significance of resistance. Enferm Infecc Microbiol Clin. 23(4):3-8. https://doi.org/10.1157/13091442

Altizer, S., Dobson, A., Hosseini, P., Hudson, P., Pascual, M., \& Rohani, P. (2006). Seasonality and the dynamics of infectious diseases. Ecol Lett. 9:467-84. https://doi.org/10.1111/j.1461-0248.2005.00879.x

Apolinário, T. A., Campos, K. A. M. S., Tavares, B., Agostinho, L. A., \& Fernandes, F. M. (2014). Prevalência de infecção urinária e resistência a antimicrobianos em um grupo de gestantes. Rev Cientifica da https://periodicos.faminas.edu.br/index.php/RCFaminas/article/view/344/319

Araujo, K. L. \& Queiroz, A. C. (2012). Análise do perfil dos agentes causadores de infecção do trato urinário e dos pacientes portadores, atendidos no Hospital e Maternidade Metropolitano - SP. J Health Sci Inst, 30(1):7-12. https://repositorio.unip.br/wp-content/uploads/2020/12/V30_n1_2011_p7-12.pdf

Araújo, M. Q., Carvalhais, R. P., Faria, S. O., Marinho, M. F., Santos, F. M., Santos, T. G. Q. A., et al. (2017). Perfil de resistência bacteriana em fômites de UTI em hospital público do estado do Tocantins. Rev Cereus. 9(2):126-41. http://ojs.unirg.edu.br/index.php/1/article/view/1576

Bauer, A. W. \& Kirby, E. M. (1966). Antibiotic Susceptibility Testing by Standardized Single Disk Method. American Journal of Clinical Pathology, 45(4):493-496. https://doi.org/10.1093/ajcp/45.4_ts.493

Braggiato, C. R. \& Lazar, C. A. E. L. (2016). Infecções do trato urinário não complicada na mulher: relato de caso e revisão de literatura. Rev da Faculdade de Ciências Médicas de Sorocaba. 18(4):1-4. https://doi.org/10.5327/Z1984-4840201623669

Brambilla, G. G., et al. (2019). Incidência de microrganismos em infecções no trato urinário e sua relação com o antibiograma em um laboratório da região do noroeste do paraná. Rev. UNINGÁ, 56(4):85-97. http://revista.uninga.br/index.php/uninga/article/view/2743

Brasil. Agência Nacional de Vigilância Sanitária. (2013). Microbiologia Clínica para o Controle de Infecção Relacionada à Assistência à Saúde. Módulo 3: Principais Síndromes Infecciosas/Agência Nacional de $\quad$ Vigilância Sanitária. https://www.saude.go.gov.br/images/imagens_migradas/upload/arquivos/2017-02/modulo-3---principais-sindromes-infecciosas.pdf

Carvalho, F. L. O. et al. (2018). Infecção urinária de repetição e os aspectos gerais, microbiológicos e imunológicos associados à saúde da mulher. Revista de Saúde ReAGES, [S.1.], 1(3):24-30. https://docplayer.com.br/116693980-Infeccao-urinaria-de-repeticao-e-os-aspectos-gerais-microbiologi-cos-e-imunologicosassociados-a-saude-da-mulher.html

Catto, A. J. A. et al. (2016). Prevalência e perfil de resistência de escherichia coli em uroculturas positivas no município de Triunfo/RS. Rev AMRIGS. 60(1):21-25. https://www.amrigs.org.br/revista/60-01/04.pdf

Cervo, A. L. \& Bervian, P. A. (2002). Metodologia científica. 5.ed. Prentice Hall.

Clinical and Laboratory Standards Institute (CLSI). (2014). Performance Standards for Antimicrobial Susceptibility Testing; Twenty-Fourth Informational Supplement, Document M100-S24.Wayne: CLSI; 34(1):1-230. https://clsi.org/media/2663/m100ed29_sample.pdf

Clsi - Clinical and Laboratory Standards Institute. (2012). Performance standards for antimicrobial susceptibility testing: twenty-second informational supplement. M100-S22. https://www.scienceopen.com/document?vid=cafe92ec-d545-40a5-917d-0e960305bed0

Delgado, M. (2021). Centro Brasileiro de Urologia. O inverno favorece a infecção urinária. Disponível em: https://centrobrasileirodeurologia.com.br/litiase/infeccao-urinaria/ Acesso em: 26 jan. 2021.

Dias, I. O. V., Coelho, A. M., \& Dorigon, I. (2015). Infecção do trato urinário em pacientes ambulatoriais: prevalência e perfil de sensibilidade frente aos antimicrobianos no período de 2009 a 2012. Saúde, 41(1):209-218. https://doi.org/10.5902/2236583415455

Duarte, G. Marcolin, A. C. Quintana, S. M. \& Cavalli, R. C. (2008). Infecção urinária na gravidez. RevBrasGinecol Obstet. 30(2):93-100. https://doi.org/10.1590/S0100-72032008000200008

Figueiredo, A., Gomes, G., \& Campos, A. (2012). Urinary tract infections in pregnancy - diagnosis treatment and prevention. Acta ObstetGinecol Port. 6(3):124-33. https://doi.org/10.1016/s0924-8579(00)00354-X

Fisman, D. N. (2007). Seasonality of infectious diseases. Annu Rev Public Health. 28:127-43.

Grillo, V. T. R. D. S., Gonçalves, T. G., Campos, J. J., Paniágua, N. C., \& Teles, C. B. G. (2013). Incidência bacteriana e perfil de resistência a antimicrobianos em pacientes pediátricos de um hospital público de Rondônia, Brasil. Rev Ciênc Farm Básica Apl. 34(1):117-23. https://doi.org/10.1146/annurev.publhealth.28.021406.144128

Houaiss, A. (2001). Dicionário Houaiss da língua portuguesa. Objetiva.

Instituto Brasileiro de Geografia e Estatística Brasil/IBGE. (2019). Minas Gerais/ Conselheiro Lafaiete. https://cidades.ibge.gov.br/brasil/mg/conselheirolafaiete/pesquisa/33/29171?tipo=ra nking

Kadosaki, L. L.; Sousa, S. F.; \& Borges, J. C. M. (2012). Análise do uso e da resistência bacteriana aos antimicrobianos em nível hospitalar. Rev Bras Farm, 93(2):128-135. https://adm.online.unip.br/img_ead_dp/60614.pdf 
Research, Society and Development, v. 11, n. 1, e32811124855, 2022

(CC BY 4.0) | ISSN 2525-3409 | DOI: http://dx.doi.org/10.33448/rsd-v11i1.24855

Kaper, J. B., Nataro, J. P., \& Mobley, H. L. T. (2004). Pathogenic Escherichia coli. NatRev Microbiol. 2:123-40. https://doi.org/10.1038/nrmicro818 Koneman, E. W. (2008). Diagnóstico microbiológico - Texto e atlas colorido. 6.ed. Guanabara Koogan. 1465-65.

Lakatos, E. M.; Marconi, M. A. (2001). Fundamentos metodologia científica. 4ed. Atlas.

Lima, A. D. P. (2017). Perfil de infecções bacterianas do trato urinário e resistência aos antibióticos. https://repositorio.ufu.br/bitstream/123456789/20721/5/PerfilInfec\%C3\%A7\%C 3\%B5esBacterianas.pdf

Lima, A. R. V \& Lima, L. R. (2018). Infecção urinária na gestação: Uma revisão de literatura. Mostra Interdisciplinar do curso de Enfermagem. http://publicacoesacademicas.unicatolicaquixada.edu.br/index.php/mice/article/vi ew/2915

Loureiro, R. J., Roque, F., Rodrigues, A. T., Herdeiro, M. T., \& Ramalheira, E. (2016). O uso de antibióticos e as resistências bacterianas: breves notas sobre a sua evolução. Revista Portuguesa de Saúde Pública. 34(1);77-84. https://doi.org/10.1016/j.rpsp.2015.11.003

Machado, P. A. et al. (2017). Prevalência de infecções do trato urinário e perfil de susceptibilidade a antimicrobianos de bactérias isoladas. Disciplinarum Scientia. Série: Ciências da Saúde, Santa Maria, 18(2):271-287. https://periodicos.ufn.edu.br/index.php/disciplinarumS/article/view/2059/2078

Masson, P. et al. (2009). Meta analyses in Prevention and Treatment of Urinary Tract Infections. Infectious Disease Clinics of North America, 23 (2):355-85. https://doi.org/10.1016/j.idc.2009.01.001

Menin, V. T. \& Grazziotin, N. A. (2010). Infecções do Trato Urinário Diagnosticadas no Laboratório Universitário da URI - Campus de Erechim/RS. Revista Brasileira de Análises Clínicas. 42(4): 307-10. https://www.sbac.org.br/Infecções_do_Trato_Urinário_Diagnosticadas_no_Laboratório_Universitário_da_URI

Moura, L. B. (2011). A incidência de infecções urinárias causadas por E. coli. Revista Olhar Científico, 1(2):411-26. https://doi.org/10.33362/ries.v3i2.182

Oliveira, S. M, \& Santos, L. L. G. (2018). Infecção do trato urinário: estudo epidemiológico em prontuários laboratoriais. Journal Health NPEPS. 3(1):198210. https://periodicos.unemat.br/index.php/jhnpeps/article/view/2843

Piçarra, A. M. F. (2015). Infecções Urinárias: Aspetos Microbiológicos e Epidemiológicos. [Dissertação de Mestrado, Universidade Lusófona de Humanidades e Tecnologias]. https://oasisbr.ibict.br/vufind/Record/RCAP_0710d60f94c4a03b0127d4364d154a4e

Pires, M. C. S., Frota, K. S., Martins, P. O. J., Correia, A. F., Cortez-Escalante, J. J., \& Silveira, C. A. (2007). Prevalência e suscetibilidades bacterianas das infecções comunitárias do trato urinário, em hospital universitário de Brasília, no período de 2001 a 2005. Rev Soc Bras Med Trop. 40(6):643-7. https://doi.org/10.1590/S0037-86822007000600009

Richardson, R. J. (1999). Pesquisa social: métodos e técnicas. 3ed. Atlas.

Rodrigues, F. S. (2018). Fatores Associados à Aquisição Nosocomial de Bacilos Gram-Negativos no Hospital das Clínicas da Faculdade de Medicina de Botucatu em Diferentes Estações do Ano: Um Estudo Tipo Caso-Caso. [Dissertação de Mestrado, Universidade Estadual Paulista]. https://repositorio.unesp.br/bitstream/handle/11449/153211/rodrigues_fs_me_bot_int.pdf?sequence=4\&isAllowed=y

Roriz, J. S. F., Vilar, F. C., Mota, L. M., Leal, C. L., \& Pisi, P. C. B. (2010). Infecção do trato urinário. Rev USP. 43(2):118-25. https://doi.org/10.11606/issn.2176-7262.v43i2p118-125

Rouquayrol, M. Z. (1999). Epidemiologia descritiva. Médica e Científica.

Santana, T. C. F. S. et al. (2012). Prevalência e resistência bacteriana aos agentes antimicrobianos de primeira escolha nas infecções do trato urinário no município de São Luís-MA. Revista de Patologia Tropical, 41(4):409-18. https://doi.org/10.5216/rpt.v41i4.21704

Santos, T. K. P., Sanches, I. T., Pittner, E., \& Sanches, H. F. (2012). Identificação e perfil antimicrobiano de bactérias isoladas de urina de gestação atendidas na irmandade da Santa Casa de misericórdia de Prudentópolis, Paraná. Semina: Ciências Biológicas e da Saúde. 33(2):181-92. https://doi.org/10.5433/1679$0367.2012 \mathrm{v} 33 \mathrm{n} 2 \mathrm{p} 181$

Schenkel, D. F., Dallé, J., \& Antonello, V. S. (2014). Microbial etiology and susceptibility of community urinary tract infections during pregnancy in the South of Brazil. Rev Bras Ginecol Obstet. 36(3):102-6. https://doi.org/10.1590/s0100-72032014000300002

Tortora G. J., Funke B. R., \& Case C. L. (2017). Doenças Microbianas dos Sistemas Urinário e reprodutor. In: Tortora GJ, Funke BR, Case CL. Microbiologia. Tradução Roberta Marchiori Martins. Artmed. 